\title{
Insulin resistance (HOMA-IR) cut-off values and the metabolic syndrome in a general adult population: effect of gender and age: EPIRCE cross-sectional study
}

Pilar Gayoso-Diz ${ }^{1,2 *}$, Alfonso Otero-González ${ }^{3}$, María Xosé Rodriguez-Alvarez ${ }^{1,2}$, Francisco Gude ${ }^{1,2}$, Fernando García ${ }^{4}$, Angel De Francisco ${ }^{5}$ and Arturo González Quintela ${ }^{1,2}$

\begin{abstract}
Background: Insulin resistance has been associated with metabolic and hemodynamic alterations and higher cardio metabolic risk. There is great variability in the threshold homeostasis model assessment of insulin resistance (HOMA-IR) levels to define insulin resistance. The purpose of this study was to describe the influence of age and gender in the estimation of HOMA-IR optimal cut-off values to identify subjects with higher cardio metabolic risk in a general adult population.

Methods: It included 2459 adults (range 20-92 years, 58.4\% women) in a random Spanish population sample. As an accurate indicator of cardio metabolic risk, Metabolic Syndrome (MetS), both by International Diabetes Federation criteria and by Adult Treatment Panel III criteria, were used. The effect of age was analyzed in individuals with and without diabetes mellitus separately. ROC regression methodology was used to evaluate the effect of age on HOMA-IR performance in classifying cardio metabolic risk.

Results: In Spanish population the threshold value of HOMA-IR drops from 3.46 using 90th percentile criteria to 2.05 taking into account of MetS components. In non-diabetic women, but no in men, we found a significant non-linear effect of age on the accuracy of HOMA-IR. In non-diabetic men, the cut-off values were 1.85. All values are between 70th-75th percentiles of HOMA-IR levels in adult Spanish population.

Conclusions: The consideration of the cardio metabolic risk to establish the cut-off points of HOMA-IR, to define insulin resistance instead of using a percentile of the population distribution, would increase its clinical utility in identifying those patients in whom the presence of multiple metabolic risk factors imparts an increased metabolic and cardiovascular risk. The threshold levels must be modified by age in non-diabetic women.
\end{abstract}

Keywords: Insulin resistance, Gender, Cardio metabolic risk, Metabolic syndrome

\section{Background}

Insulin resistance (IR) is a feature of disorders such as diabetes mellitus type 2 (DM2) and is also implicated in obesity, hypertension, cancer or autoimmune diseases [1-3]. Insulin resistance (IR) has been proposed, more than a primary cause, as a sort of final common pathway for negative

\footnotetext{
* Correspondence: pilar.gayoso.diz@sergas.es

'Clinical Epidemiology Unit, Hospital Clínico Universitario, A Choupana, s/n,

15706, Santiago de Compostela, Spain

${ }^{2}$ Instituto de Investigación Sanitaria de Santiago (IDIS), Santiago de

Compostela, Spain

Full list of author information is available at the end of the article
}

environmental factors, which interact with the individual genetic background to cause metabolic and hemodynamic alterations and is associated with inflammation $[4,5]$.

Metabolic syndrome (MetS) definition is widely used as a practical tool to describe a cluster of clinical signs (central obesity, dyslipidemia, impaired glucose metabolism, and elevated blood pressure) that regardless of cause, identifies individuals at risk of atherosclerotic cardiovascular disease (CVD), and DM2 [6-9]. The worldwide prevalence of these factors has risen dramatically in recent decades [10-12].

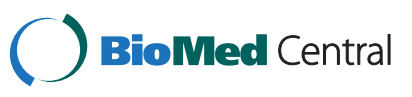


The Homeostasis Model Assessment of IR (HOMA-IR) has proved to be a robust tool for the surrogate assessment of IR $[13,14]$. However, there is great variability in the threshold HOMA-IR levels to define IR. Population based studies for defining cut-off values of HOMA-IR for the diagnosis of IR had been conducted in different geographic areas [15-22]. Table 1 shows the cut-off values, as can be seen in most of cases the cutoff point's determination were made on the percentile criterion ( 80 or 90 according to studies) of values in the general population. However, no studies have examined the ability of proposed cutoff points to identify risk of clinically relevant outcomes [14]. In addition, in these studies the results have been reported without taking into account the possible effects of covariates on test results. However, it is well known that a biomarker's performance and, by extension, its discriminatory capacity can be affected by covariates [23].

In a previous study we showed that there are age and gender-specific differences in HOMA-IR levels, with increased levels in women over fifty years of age [24]. On the other hand, the prevalence of cardio metabolic diseases such as diabetes or central obesity rises with age and shows gender differences [11,12]. All these results suggest the possible effects of both age and gender on the accuracy of HOMA-IR to identify individuals with cardio metabolic risk.

The purpose of the present population-based study was to evaluate the change in defining cut-off values of HOMA-IR for the diagnosis of IR when cardio metabolic risk factors were considered. We currently assess the influence of age and gender on the performance of HOMA-IR levels to identify cardio metabolic risk in an adult population, to better understand the relationship between insulin resistance and cardio metabolic risk.

\section{Methods}

\section{Setting}

The present study was a secondary analysis of data from a survey of the Spanish general adult population (EPIRCE) $[25,26]$. The EPIRCE is an observational, cross-sectional study that included a randomly selected sample of Spanish persons aged 20 years and older stratified by age, gender, and habitat. The study was primarily intended to investigate the prevalence of chronic kidney disease (CKD) in the Spanish adult population. Details of the study design were previously published [26].

For the present study, data analysis could not be performed in 249 individuals (9.1\%) because of a lack of insulin level recording and in 38 (1.4\%) individuals because of a lack of waist circumference recording. There were no statistically significant differences between individuals with or without missing data regarding age, gender, hypertension, alcohol intake, or physical activity. Finally, 2459 individuals were selected for study inclusion. People with diabetes (247, $10.0 \%$ ), defined as a fasting plasma glucose $\geq 7.0 \mathrm{mmol} \mathrm{l}^{-1}$ and/or the current use of diabetes medications (32, 1.3\%), were included. The average age was $49.4 \pm 16.2$ years (range 20-92 years). A total of 1436 (58.4\%) were women. All participants were Caucasians.

\section{Anthropometric and clinical measurements}

Subjects were considered to have hypertension if they had a mean systolic blood pressure (SBP) $\geq 140 \mathrm{mmHg}$ and/or diastolic blood pressure (DBP) $\geq 90 \mathrm{mmHg}$ or used antihypertensive medications.

Table 1 Summary of reports (sorted by sample size) on HOMA-IR cut-off in different populations

\begin{tabular}{|c|c|c|c|}
\hline Study & Characteristics of study population & Threshold value & Criteria \\
\hline Hedblad, 2000 [15] & $N=4,816$ Sweden, population-based sample & $\geq 2.0$ & 75th percentile \\
\hline Summer, 2008 [16] & $\mathrm{N}=2804$, U.S. NHANES population, age $\geq 20 \mathrm{yr}$. normal BMl and fasting glucose & $\geq 2.73$ & 66th percentile \\
\hline Geloneze, 2006 [17] & $\mathrm{N}=1317$ Brazilian, age: $40 \pm 12 \mathrm{yr}, \mathrm{BMI}: 34 \pm 10 \mathrm{~kg} / \mathrm{m}^{2}$ & $\geq 2.77$ & 90th percentile \\
\hline \multirow[t]{5}{*}{ Esteghamati, 2009 [18] } & $N=1,276$ Iranian, & $\geq 1.80$ & $\mathrm{ROC}$ \\
\hline & Age: $38 \pm 12$ yr, non-diabetic, normotensive & $\geq 1.95$ & $\mathrm{ROC}$ \\
\hline & IDF-MetS & $\geq 1.6$ & 75th percentile \\
\hline & ATPIII-MetS & $\geq 1.8$ & 80th percentile \\
\hline & & $\geq 2.3$ & 90th percentile \\
\hline Marques-Vidal, 2002 [19] & $N=1153$, France, age: $35-64$ yr, population based sample & $\geq 3.8$ & 75th percentile \\
\hline Do, 2010 [20] & $\mathrm{N}=738$ Thailand, age: $\geq 35 \mathrm{yr}$, normal $\mathrm{BMl}$ and fasting glucose & 1.55 & 90th percentile \\
\hline Miccoli, 2005 [38] & $N=225$ Italian, age: $40-79 \mathrm{yr}$, healthy subjects & $\geq 2.77$ & 80th percentile \\
\hline Nakai, 2002 [22] & $N=161$ Japanese, age: $41.6 \pm 0.4 \mathrm{yr}$, healthy subjects & $\geq 1.7$ & 90th percentile \\
\hline Ascaso, 2001 [39] & $N=140$ Spanish, age: $7-16 \mathrm{yr}$ & 3 & $\mathrm{ROC}$ \\
\hline Tome, 2009 [40] & $\mathrm{N}=2860$ Spanish, population based age: 18-104 yr, BMI: $26.2 \pm 4.9 \mathrm{~kg} / \mathrm{m}^{2}$ & 2 & $\mathrm{ROC}$ \\
\hline
\end{tabular}


Waist circumference and body weight and height were measured according to a standard protocol. To measure the waist circumference all researchers followed these instructions: Locate the top of the hip bone (iliac crest) and take the measurement just above this bony landmark, just where one finger can fit between the iliac crest and the lowest rib. Ensure that the tape measure is positioned horizontally, parallel to the floor. Measuring at a level just above the iliac crest, and positioning the tape horizontally, irrespective of whether the umbilicus is above or below the tape, provides the correct waist circumference measurement and should correspond to the maximal abdominal diameter. Ensure that the patient is standing erect and has relaxed the abdominal muscles. Measurement must be taken at the end of normal expiration. The body mass index (BMI) was calculated as the weight $(\mathrm{kg})$ divided by the square of the height (meters).

\section{Specific laboratory determinations}

A blood sample was collected after an overnight fast of $>8$ h. Plasma glucose levels were measured using a hexokinase enzymatic reference method. Fasting insulin levels were measured using a radioimmunoassay (RIA) method (Coat A Count Insulin, Los Angeles, USA). Fasting lipids were analyzed, and for the present study serum levels of cholesterol $\geq 5.172 \mathrm{mmol} \mathrm{l}^{-1}$ and triglycerides $\geq 1.7 \mathrm{mmol} \mathrm{l}^{-1}$ were considered abnormal.

HOMA-IR was used to evaluate insulin resistance (fasting serum insulin $(\mu \mathrm{U} / \mathrm{ml}) \times$ fasting plasma glucose $\left.\left(\mathrm{mmol} \mathrm{l}^{-1}\right) / 22.5\right)[27]$.

\section{Definition of metabolic syndrome}

As an accurate indicator of cardio metabolic risk, MetS, both by the International Diabetes Federation (IDF) criteria and by the Adult Treatment Panel III (ATP III) criteria, were used. Under the IDF criteria, MetS $\left(\mathrm{MetS}_{\mathrm{IDF}}\right)$ was defined as the presence of central obesity (waist circumference $\geq 94 \mathrm{~cm}$ for men and $\geq 80 \mathrm{~cm}$ for women) plus any two of the following risk factors: HDL-cholesterol $<1.03 \mathrm{mmol} \mathrm{l}^{-1}$ (males) and $<1.29 \mathrm{mmol} \mathrm{l}^{-1}$ (females) or specific treatment for this lipid abnormality; systolic blood pressure $\geq 130$ or diastolic blood pressure $\geq 85 \mathrm{~mm} \mathrm{Hg}$, or treatment of previously diagnosed hypertension; fasting plasma glucose $\geq 5.6 \mathrm{mmol} \mathrm{l}^{-1}$, or previously diagnosed type 2 diabetes; triglycerides $\geq 1.7 \mathrm{mmol} \mathrm{l}^{-1}$ or specific treatment for this lipid abnormality [28]. According to ATPIII criteria, MetS $\left(\mathrm{MetS}_{\mathrm{ATPII}}\right)$ was defined as the presence of three or more of the following: HDLcholesterol $<1.03 \mathrm{mmol} \mathrm{l}^{-1}$ (males) and $<1.30 \mathrm{mmol} \mathrm{l}^{-1}$ (females) or specific treatment for this lipid abnormality; blood pressure $\geq 130 / 85 \mathrm{~mm} \mathrm{Hg}$ or treatment of previously diagnosed hypertension; fasting plasma glucose $\geq 5.6 \mathrm{mmol} \mathrm{l}^{-1}$, or previously diagnosed type 2 diabetes; triglycerides $\geq 1.7 \mathrm{mmol} \mathrm{l}^{-1}$ or specific treatment for this lipid abnormality; waist circumference $\geq 102 \mathrm{~cm}$ for males and $\geq 88 \mathrm{~cm}$ for females [29].

\section{Statistical analyses}

Baseline subject characteristics are expressed as the mean \pm SD or as percentages. Cross-tabulation significance levels were based on Pearson's chi-square test for categorical variables. The Mann-Whitney U-test and KruskallWallis test were employed for comparison of quantitative variables. Although normally distribution of quantitative variables were verified, non parametric test were used because they are less likely than the parametric test to spuriously indicate significance due to the presence of outliers, they are more robust.

To analyze the effect of age on the accuracy of HOMAIR when predicting the presence of cardio metabolic risk, a novel non-parametric extension [30] of the induced ROC regression methodology [23,31] was used. Since it is well established that HOMA-IR values behave differently according to gender and diabetes status, the analyses were performed separately in men and in women and in diabetic and non-diabetic individuals. We evaluate the significant effect of age on the accuracy of HOMA-IR and P-values were obtained based on 200 bootstrap replications [30].

When the estimated effect of age on the mean of HOMAIR probed to be linear, and the estimated variances probed to be constant (independent of age), we reanalyzed the data using the semi-parametric induced ROC regression [23,32].

Finally, in addition to the estimated (age-specific) ROC curve, the Area Under the Curve (AUC) and bootstrap-based confidence intervals were obtained, ( $b=500$ resamples). The (age-specific) threshold values were also computed based on two different criteria: (a) by setting the specificity at 0.7 , and (b) by the Youden Index (YI). Insofar as the computation of the YI is concerned, in those situations where a significant effect of age was detected on the accuracy of HOMA-IR, a modification of the usual definition was used, which takes covariates into account.

All statistical analyses were performed using $\mathrm{R}$ software, version 2.12.1 [33]. ROC analyses were performed using the packages pROC [34], ROCRegression and npROCRegression. These last two packages can be obtained by contacting MX Rodriguez-Alvarez (mxrodriguez@uvigo.es).

\section{Ethical considerations}

The Galician Ethical Committee for Clinical Research approved the study protocol. All patients provided informed consent.

\section{Results}

Table 2 summarizes anthropometric, clinical, and biochemical characteristics of the study sample. In the overall data set, the MetS prevalence was $15 \%$ for MetS $_{\text {IDF }}$ $(19.2 \%$ in men vs. $12.1 \%$ in women, $\mathrm{P}<0.0001)$ and 
Table 2 Anthropometric, clinical, and biochemical characteristics of patient sample: distribution by gender in diabetic ( $n=247)$ and non-diabetic $(n=2212)$ individuals

\begin{tabular}{|c|c|c|c|}
\hline & Women $(1308 / 128)$ & Men $(904 / 119)$ & Total \\
\hline \multicolumn{4}{|l|}{ Age (years) } \\
\hline - Non-diabetic & $47.6 \pm 15.9$ & $48.2 \pm 16.0$ & $47.9 \pm 15.9$ \\
\hline - Diabetic & $64.4 \pm 10.7$ & $62.4 \pm 10.8$ & $63.4 \pm 10.7$ \\
\hline \multicolumn{4}{|c|}{ Waist circumference (cm) } \\
\hline - Non-diabetic ${ }^{* * *}$ & $86.8 \pm 13.2$ & $96.3 \pm 11.3$ & $90.6 \pm 13.3$ \\
\hline - Diabetic* & $101.5 \pm 13.5$ & $105.0 \pm 11.4$ & $103.1 \pm 12.5$ \\
\hline \multicolumn{4}{|l|}{ BMI $\left(\mathrm{kg} / \mathrm{m}^{2}\right)$} \\
\hline - Non-diabetic ${ }^{* * *}$ & $26.9 \pm 5.4$ & $27.8 \pm 4.5$ & $27.3 \pm 5.1$ \\
\hline - Diabetic ${ }^{* * *}$ & $32.2 \pm 5.6$ & $29.4 \pm 4.4$ & $31.1 \pm 5.2$ \\
\hline \multicolumn{4}{|c|}{ Systolic blood pressure (mmHg) } \\
\hline - Non-diabetic ${ }^{* * *}$ & $125.4 \pm 21.0$ & $135.8 \pm 19.0$ & $129.6 \pm 20.8$ \\
\hline - Diabetic & $145.9 \pm 21.1$ & $148.6 \pm 21.2$ & $147.3 \pm 21.1$ \\
\hline \multicolumn{4}{|c|}{ Diastolic blood pressure $(\mathrm{mmHg})$} \\
\hline - Non-diabetic*** & $76.6 \pm 11.0$ & $81.1 \pm 11.4$ & $78.4 \pm 11.4$ \\
\hline - Diabetic & $82.1 \pm 11.7$ & $82.1 \pm 10.7$ & $82.1 \pm 11.2$ \\
\hline \multicolumn{4}{|c|}{ Triglycerides $\left(\mathrm{mmol} \mathrm{I}{ }^{-1}\right)$} \\
\hline - Non-diabetic ${ }^{* * *}$ & $1.0 \pm 0.6$ & $1.3 \pm 0.9$ & $1.1 \pm 0.7$ \\
\hline - Diabetic & $1.5 \pm 0.8$ & $1.9 \pm 1.9$ & $1.7 \pm 1.4$ \\
\hline \multicolumn{4}{|c|}{ HDL-Cholesterol (mmol/L) } \\
\hline - Non-diabetic ${ }^{* * *}$ & $2.0 \pm 0.5$ & $1.7 \pm 0.4$ & $1.9 \pm 0.5$ \\
\hline - Diabetic ${ }^{* *}$ & $1.7 \pm 0.4$ & $1.6 \pm 0.4$ & $1.8 \pm 0.4$ \\
\hline \multicolumn{4}{|l|}{ Fasting insulin (U/I) } \\
\hline - Non-diabetic ${ }^{* *}$ & $7.7 \pm 4.6$ & $8.5 \pm 5.2$ & $8.0 \pm 4.9$ \\
\hline - Diabetic & $11.9 \pm 6.2$ & $10.9 \pm 6.5$ & $11.4 \pm 6.3$ \\
\hline \multicolumn{4}{|c|}{ Fasting plasma glucose $\left(\mathrm{mmol} \mathrm{I}^{-1}\right)$} \\
\hline - Non-diabetic ${ }^{* * *}$ & $4.9 \pm 0.6$ & $5.1 \pm 0.6$ & $5.0 \pm 0.6$ \\
\hline - Diabetic* & $7.8 \pm 2.4$ & $8.1 \pm 2.5$ & $8.0 \pm 2.5$ \\
\hline \multicolumn{4}{|l|}{ HOMA-IR (units) } \\
\hline - Non-diabetic & $1.9 \pm 1.0$ & $2.1 \pm 1.2$ & $2.0 \pm 1.1$ \\
\hline - Diabetic ${ }^{*}$ & $1.9 \pm 1.0$ & $1.7 \pm 1.1$ & $1.9 \pm 1.1$ \\
\hline \multicolumn{4}{|c|}{ Metabolic syndrome } \\
\hline ATPIII** & $11.1 \%(159)$ & $14.9 \%(152)$ & $12.7 \%(311)$ \\
\hline - Non-diabetic ${ }^{* *}$ & $7.6 \%(99)$ & $11.1 \%(100)$ & $9.0 \%(199)$ \\
\hline - Diabetic & $46.9 \%(60)$ & $43.7 \%(52)$ & $45.3 \%(112)$ \\
\hline IDF*** & $12.1 \%(174)$ & $19.2 \%(196)$ & $15.0 \%(370)$ \\
\hline - Non-diabetic ${ }^{* * *}$ & $8.7 \%(114)$ & $14.9 \%(135)$ & $11.3 \%(249)$ \\
\hline - Diabetic & $46.9 \%(60)$ & $51.3 \%(61)$ & $49.0 \%(121)$ \\
\hline
\end{tabular}

Data are presented as mean \pm standard deviation, or percentages (n). BMI, body mass index; HDL-Cholesterol, high density lipoprotein-Cholesterol; HOMA-IR, homeostasis model assessment of IR; ATPIII, Third Adult Treatment Panel; IDF, International Diabetes Federation.

Contrast of characteristics by gender was done with the follow statistical significance: ${ }^{*} p<0.05,{ }^{* *} p<0.01,{ }^{* * *} p<0.001$.

$12.7 \%$ for $\mathrm{MetS}_{\text {ATPIII }}(14.9 \%$ in men vs. $11.1 \%$ in women, $\mathrm{P}=0.006)$. In non-diabetic individuals, but not in diabetic individuals, we found significant differences by gender in components of MetS (data no shown). The percentage of men with positive MetS components of higher triglycerides, blood pressure, and glycemia were significantly higher than women ( $23 \%$ vs. $9.6 \%(\mathrm{P}<0.001), 32 \%$ vs. $19 \%(\mathrm{P}<0.001)$ and $21 \%$ vs. $13 \%(\mathrm{P}<0.001))$. In contrast, women with 
positive MetS component of larger waist circumference were significantly higher than men (43.6\% vs. $29.8 \%$, ATPIII criteria, $\mathrm{P}<0.0001$ and $52.7 \%$ vs. $35.1 \%$, IDF criteria, $\mathrm{P}<0.001)$.

Mean HOMA-IR levels significantly increased with rising number of MetS components from 1.7 (without MetS components) to 5.3 (with 5 components) $(\mathrm{P}<0.0001)$.

AUC values of HOMA-IR by age, gender and diabetes status The results of the effects of age and gender on the accuracy of HOMA-IR (AUC values) among non-diabetic and diabetic individuals were presented in Table 3. Meanwhile, Figure 1 shows the estimated AUC values by age, with the corresponding $95 \%$ point wise bootstrap confidence band in non-diabetic men and women. Regardless of diabetes status, the AUC values of HOMA-IR were slightly higher for MetS $_{\text {ATPIII }}$ than MetS $_{\text {IDF }}$ (Table 3). The effect of age on the accuracy of HOMA-IR was analyzed in individuals with and without diabetes mellitus separately. As can be seen in Table 3, in non-diabetic women a significant non-linear effect of age on the accuracy of HOMA-IR in identifying MetS, both $\operatorname{MetS}_{\text {ATPIII }}(\mathrm{P}=0.012)$ and $\operatorname{MetS}_{\text {IDF }}(\mathrm{P}<0.001)$, was found. The AUC presents a plateau with values greater than 0.7 until 50 years of age. From the age of 50, the AUC decreases progressively. For patients older than 70 years, the bootstrap confidence intervals for the AUC includes 0.5; thus there is no evidence suggesting that HOMA-IR can be used to classify non-diabetic older women with cardio metabolic risk. Table 3 shows the estimated AUC values for ages of 30,50 , and 70 years in our Spanish population. The AUC drops from 0.82 (age 30) to 0.58 (age 70).

However, in non-diabetic men the AUC progressively decreases with age, without statistical significance $(\mathrm{P}=0.16$, Figure 1). Thus AUC value, $0.69(0.65,0.74)$ for $\mathrm{Met}_{\mathrm{IDF}}$ and $0.71(0.66,0.76)$ for $\mathrm{MetS}_{\text {ATPIII }}$, was estimated without covariates (Table 3).

On the other hand, in diabetic individuals there was no statistically significant effect of age on the accuracy of HOMA-IR. The AUC show an acceptable performance of HOMA-IR in diabetic men, $0.7(0.6,0.8)$, but not in diabetic women $0.54(0.44,0.64)$ (Table 3$)$.

\section{Cut-off values of HOMA-IR}

Table 4 shows gender distribution of HOMA-IR cut-off values, with their corresponding sensitivity and specificity both in diabetic and non-diabetic populations. In non-diabetic individuals we found significantly differences by gender. Figure 2 depicts the estimated HOMA-IR cutoff values by age in non-diabetic women for Met $S_{\text {ATPIII }}$ and $\mathrm{MetS}_{\text {IDF }}$ respectively. For MetS $\mathrm{STPII}_{\text {the optimal }}$ HOMA-IR cut-off values ranged from 2.07 (sensitivity, 0.72 ; specificity, 0.71 ) at 50 years to 2.47 (sensitivity, 0.44; specificity, 0.74) at 70 years when using YI criteria. Very
Table 3 Performance of HOMA-IR values in the classification of cardio metabolic risk (both ATPIII MetS and IDF MetS definition), influence of age and gender

\begin{tabular}{|c|c|c|c|c|}
\hline & & ROC coefficients* & $P$ value & AUC $(95 \% \mathrm{Cl})$ \\
\hline \multirow[t]{16}{*}{ A } & Males & & & \\
\hline & IDF MetS & & & \\
\hline & - Age & 0.0102 & 0.1665 & $0.69(0.65,0.74)$ \\
\hline & - Intercept & -1.1411 & 0.0048 & \\
\hline & ATPIII Mets & & & \\
\hline & - Age & 0.0117 & 0.1897 & $0.72(0.67,0.77)$ \\
\hline & - Intercept & -1.2976 & 0.0089 & \\
\hline & Females ** & & & \\
\hline & IDF MetS & & & \\
\hline & - Age $30 \mathrm{yr}$ & & & $0.82(0.71,0.90)$ \\
\hline & - Age 50 yr & & $<0.001$ & $0.77(0.68,0.82)$ \\
\hline & - Age 70 yr & & & $0.58(0.48,0.68)$ \\
\hline & ATPIII MetS & & & \\
\hline & - Age $30 \mathrm{yr}$ & & & $0.83(0.71,0.91)$ \\
\hline & - Age $50 \mathrm{yr}$ & & 0.012 & $0.80(0.71,0.85)$ \\
\hline & - Age $70 \mathrm{yr}$ & & & $0.61(0.52,0.70)$ \\
\hline \multirow[t]{14}{*}{ B } & Males & & & \\
\hline & IDF MetS & & & \\
\hline & - Age & -0.0113 & 0.8998 & $0.68(0.59,0.78)$ \\
\hline & - Intercept & 0.1406 & 0.5160 & \\
\hline & ATPIII MetS & & & \\
\hline & - Age & -0.0029 & 0.8595 & $0.72(0.62,0.81)$ \\
\hline & - Intercept & -0.4692 & 0.6515 & \\
\hline & Females & & & \\
\hline & IDF MetS & & & \\
\hline & - Age & -0.0010 & 0.9656 & $0.54(0.44,0.64)$ \\
\hline & - Intercept & 0.0173 & 0.9914 & \\
\hline & ATPIII MetS & & & \\
\hline & - Age & -0.0010 & 0.9656 & $0.54(0.44,0.64)$ \\
\hline & - Intercept & 0.0173 & 0.9914 & \\
\hline
\end{tabular}

Areas under the ROC curves for non-diabetic $(A)$ and diabetic $(B)$ adults $(n=2459)$. AUC $(95 \% \mathrm{Cl})$, area under the ROC curve $\left(95 \%\right.$ Confidence Interval). ${ }^{*} \mathrm{ROC}$ regression models incorporating age as covariate. ${ }^{* *}$ The AUC was estimated for three ages (30,50, and 70 years) to illustrate the performance of HOMA-IR. HOMA-IR, homeostasis model assessment of IR; ATPIII, Third Adult Treatment Panel; IDF, International Diabetes Federation; MetS, Metabolic Syndrome.

similar values were found for $\mathrm{MetS}_{\mathrm{IDF}}$. On the other hand,

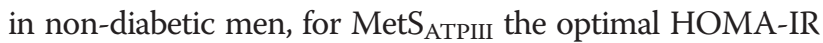
cut-off was 1.85 (sensitivity, 0.78; specificity, 0.57) when YI criteria were used and 2.27 (sensitivity, 0.61) with fixed specificity criteria. Moreover, for MetS $\mathrm{S}_{\mathrm{IDF}}$ the optimal HOMA-IR cut-off was higher, 2.05 (sensitivity, 0.65; specificity, 0.64), when YI criteria were used.

In diabetic individuals the optimal HOMA-IR cut-off value for MetS $\mathrm{S}_{\text {ATPIII }}$ was 1.60 (sensitivity, 0.63; specificity, 


\section{Women}

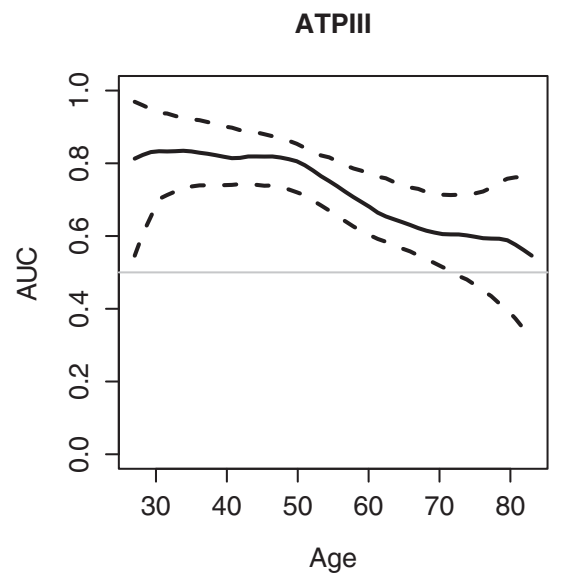

ATPIII

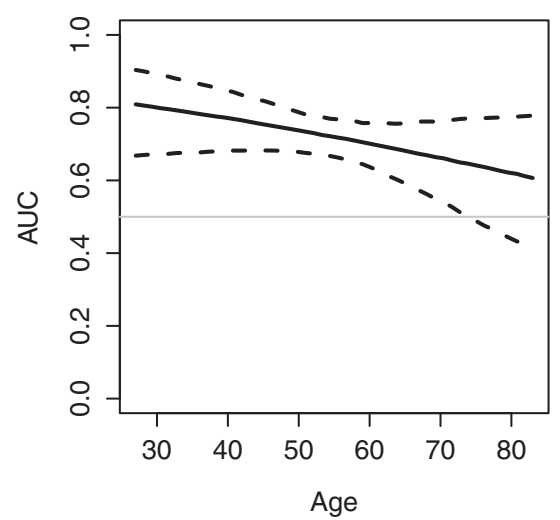

IDF

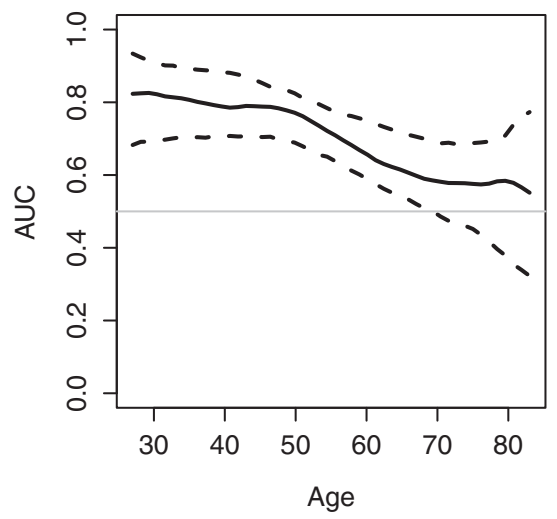

IDF

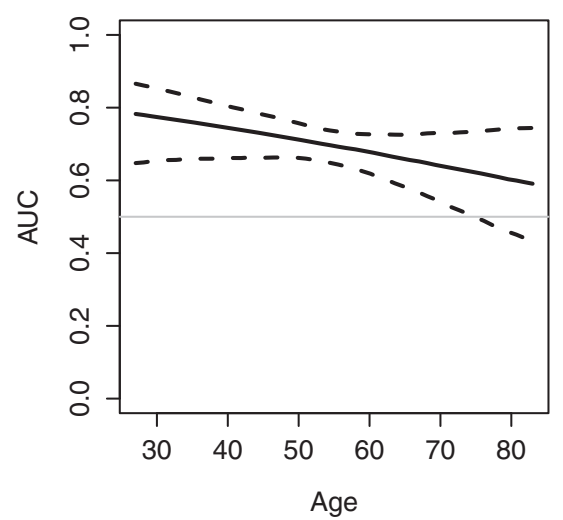

Figure 1 Performance of HOMA-IR levels for classification of cardio metabolic risk in non-diabetic population. Influence of age and gender in the area under the ROC curve (AUC), ROC regression models.

0.73 ) in men and 1.58 (sensitivity, 0.68 ; specificity, 0.46) in women (YI criteria).

\section{Discussion}

Overall, in non-diabetic individuals the best HOMA-IR cut-off levels ranged from 1.85 in men to 2.07 in women aged 50 years old for the diagnosis of IR take in account cardio metabolic risk. In women without diabetes, the optimal cutoff point should be estimated for each age group due to the non-linear effect of age on the accuracy of HOMA-IR. Even more, in women over 70 years there is no evidence suggesting that HOMA-IR can be used to classify individuals with or without cardio metabolic risk. All values are between the 70th-75th percentiles of HOMA-IR levels in the adult Spanish population [24].

We found lower cut-off values for diabetic than nondiabetic individuals (1.60 vs. 2.05 for $\mathrm{Met}_{\mathrm{IDF}}$ in men), probably because in the diabetic population there is an increased prevalence of hypertension, obesity, and dyslipidemia, thus lower HOMA-IR values identifies individuals with three or more MetS components.

In non-diabetic individuals AUC (95\%IC) was 0.69 (0.64, 0.74 ) for $\mathrm{MetS}_{\mathrm{IDF}}$ and $0.72(0.67,0.77)$ for $\mathrm{MetS}_{\mathrm{ATPIII}}$ in men and $0.77(0.68,0.82)$ for $\mathrm{MetS}_{\mathrm{IDF}}$ and $0.80(0.71,0.85)$ for $\mathrm{MetS}_{\text {ATPIII }}$ in women. These results are similar to the study by Esteghamati that found an AUC of $0.65(0.63,0.67)$ for $\mathrm{MetS}_{\mathrm{IDF}}$ and $0.68(0.66,0.70)$ for $\mathrm{MetS}_{\text {ATPIII }}$ [35].

There is a significant effect of age on the diagnostic performance of HOMA-IR levels to identify cardio metabolic risk in non-diabetic women; however, there is no evidence of a significant effect in non-diabetic men. Meanwhile, in diabetic individuals we did not find a statistically significant effect of age on the accuracy of HOMA-IR.

The AUC in non-diabetic women presents a plateau, with values greater than 0.7 , until patients are in their fifties. Recent studies reported marked gender differences with regard to degrees of IR and body composition [24,26]. The age effect found in non-diabetic women in our study may 
Table 4 Gender distribution of HOMA-IR cut-off levels, with their corresponding sensitivity and specificity,for classify of IDF MetS and ATPIII MetS, in diabetic and non-diabetic individuals

\begin{tabular}{|c|c|c|c|c|c|c|}
\hline \multicolumn{7}{|c|}{ IDF criteria } \\
\hline \multirow[t]{2}{*}{ Population } & \multicolumn{3}{|c|}{ Criterion of specificity $=0.7$} & \multicolumn{3}{|c|}{ Youden index criterion } \\
\hline & Cut point & Sensitivity & Specificity & Cut point & Sensitivity & Specificity \\
\hline \multicolumn{7}{|l|}{ Diabetic } \\
\hline Men & 1.55 & 0.60 & 0.70 & 1.60 & 0.59 & 0.74 \\
\hline Women & 2.22 & 0.37 & 0.70 & 1.58 & 0.68 & 0.46 \\
\hline \multicolumn{7}{|l|}{ Non-diabetic } \\
\hline Men & 2.25 & 0.57 & 0.70 & 2.05 & 0.65 & 0.64 \\
\hline \multicolumn{7}{|l|}{ Women* } \\
\hline 30 years & 2.11 & 0.77 & 0.70 & 2.31 & 0.71 & 0.76 \\
\hline 50 years & 2.05 & 0.69 & 0.70 & 2.05 & 0.69 & 0.70 \\
\hline 70 years & 2.38 & 0.45 & 0.70 & 2.53 & 0.40 & 0.75 \\
\hline \multicolumn{7}{|c|}{ ATP III criteria } \\
\hline \multirow[t]{2}{*}{ Population } & \multicolumn{3}{|c|}{ Criterion of specificity $=0.7$} & \multicolumn{3}{|c|}{ Youden index criterion } \\
\hline & Cut point & Sensitivity & Specificity & Cut point & Sensitivity & Specificity \\
\hline \multicolumn{7}{|l|}{ Diabetic } \\
\hline Men & 1.57 & 0.64 & 0.70 & 1.60 & 0.63 & 0.73 \\
\hline Women & 2.22 & 0.37 & 0.70 & 1.58 & 0.68 & 0.46 \\
\hline \multicolumn{7}{|l|}{ Non-diabetic } \\
\hline Men & 2.27 & 0.61 & 0.70 & 1.85 & 0.78 & 0.57 \\
\hline \multicolumn{7}{|l|}{ Women* } \\
\hline 30 years & 2.12 & 0.79 & 0.70 & 2.36 & 0.73 & 0.77 \\
\hline 50 years & 2.05 & 0.73 & 0.70 & 2.07 & 0.72 & 0.71 \\
\hline 70 years & 2.37 & 0.48 & 0.70 & 2.47 & 0.44 & 0.74 \\
\hline
\end{tabular}

*In non-diabetic females HOMA-IR cut-off values are estimated for 30, 50, and 70 years of age, because there is a non linear effect of age on test performance to classify IDF-defined MetS ( $P$ value $<0.001$ ) and ATP III-defined MetS ( $P$ value $=0.012$ ).

HOMA-IR, homeostasis model assessment of IR; ATPIII, Third Adult Treatment Panel; IDF, International Diabetes Federation; MetS, Metabolic Syndrome.

reflect the effect of menopausal changes (decreased estrogens levels and increased visceral adipose tissue, VAT) on HOMA-IR performance, with a higher utility to identify cardio metabolic risk below age 50 .

Insulin resistance increases atherogenesis and atherosclerotic plaque instability by inducing proinflammatory activities on vascular and immune cells [36,37]. HOMA-IR is a robust surrogate method to estimate IR in epidemiologic or clinical setting. However, there is great variability in their threshold levels; as can be seen in Table 1, usually the cut-off values of HOMA-IR were defined by population-based percentiles criteria. Furthermore, these cut-off values are different according to ethnicity, clinical methods of estimation, and metabolic conditions of populations studied [14]. To increase the clinical utility of HOMA-IR values, we study its ability to classify those individuals with multiple metabolic risk factors. In Spanish population the threshold value of HOMA-IR drops from 3.46 using 90th percentile criteria [24] to 2.05 take into account MetS components.

Our HOMA-IR cut-off levels are relatively low compared to those reported in a study of healthy Italian patients [38] with a value of 2.77, and in a Spanish non-diabetic population [39], with a value of 3.8. Both studies used the 80th or 90th percentile as cut-off selection criteria. On the other hand, our values are slightly higher than those reported in an Iranian population-based study with 1.77 , using YI as cut-off selection criteria [26], but in this case the value was estimated pooled in men and women.

The prevalence of MetS (15\% for IDF and $12.7 \%$ for $\left.\mathrm{Met}_{\text {ATPIII }}\right)$ was quite similar to that found in northwest Spain (18.3\% for $\mathrm{Met}_{\text {IDF }}$ and $15.0 \%$ for $\mathrm{Met}_{\mathrm{ATPIII}}$ ) [40] and in other European population-based studies [41]. On the other hand, it is significantly lower compared with the NHANES study [42], 23.7\%, and SuRFNCD-2007 study [26], 33.6\%, probably because of the higher prevalence of obesity and other metabolic alterations in US and eastern Asia compared to the Spanish population $[11,12]$.

The strengths of this study include the use of a large, diverse, and well-characterized population-based sample of adults. We used a novel non-parametric extension of the induced ROC regression methodology to analyze the effect of age on the accuracy of HOMA-IR when predicting 

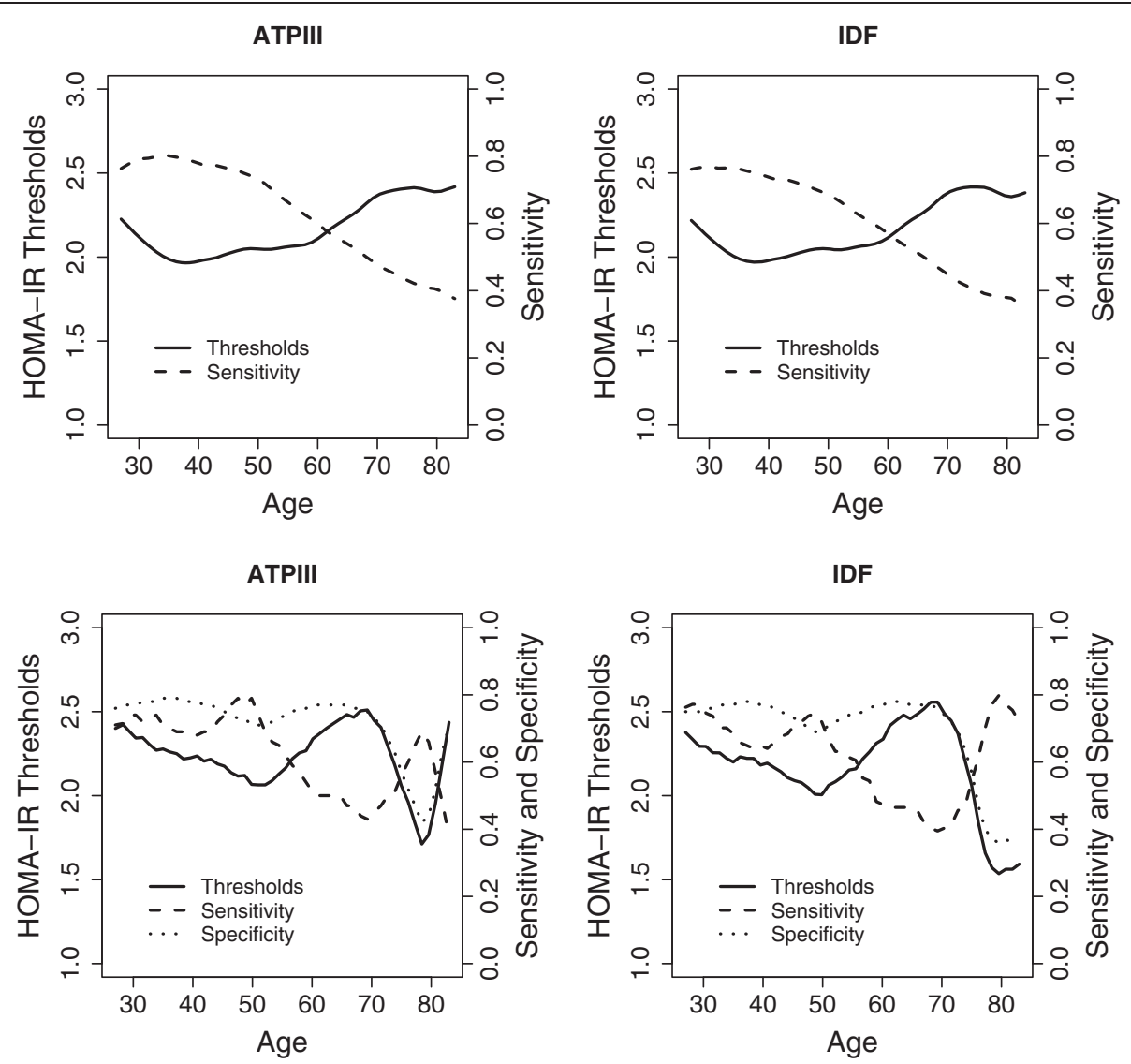

Figure 2 Optimal HOMA-IR cut point for classification of cardio metabolic risk in non-diabetic women. The top graphics show the results based on setting the specificity at 0.7 , and the bottom graphics the results based on the generalization of the Youden Index. The ATPIII-defined criteria for metabolic syndrome were used on the left, and the IDF-defined criteria for metabolic syndrome on the right.

the presence of cardio metabolic risk. The induced ROC regression methodology applied in this study is based on first evaluating the effect of covariates on the biomarker in healthy and diseased populations separately, and then computing the covariate effects on the associated ROC curve by deriving the induced form of the ROC curve.

We acknowledge limitations to our approach as well. The cross-sectional nature of our study does not allow us to draw conclusions regarding causality between IR and cardio metabolic risk. Furthermore the small sample size of diabetic patients does not allow us to draw conclusions about the performance of HOMA-IR in identifying cardio metabolic risk in diabetics. More prospective, populationbased studies are needed to elucidate these concerns.

\section{Conclusions}

We propose the addition of the components of MetS analysis as a criterion to establish the cut-off points of HOMA-IR to define IR instead of using a percentile of the population distribution. The consideration of the attendant risk of cardiovascular and metabolic diseases to establish this cut-off point would increase its clinical utility in identifying those patients in whom the presence of multiple metabolic risk factors imparts an increased metabolic and cardiovascular risk.

In summary, with the increased prevalence of obesity and diabetes [11,12], the study of IR and body composition has become an important area of research in developed countries and a central public health task.

The effect of age and gender on the ability of HOMA-IR to identify subjects with cardio metabolic risk phenotype should be taken into account in the estimation of their values in different populations. The threshold HOMA-IR levels to define IR must be modified by age in non-diabetic women.

Competing interests

All authors declare that they have no competing interests.

\section{Authors' contributions}

PG conceived of the study, and participated in its design and coordination and helped to draft the manuscript. $\mathrm{AO}$ participated in the design of the study, have made substantial contributions to acquisition of data and helped to draft the manuscript MXRA performed the statistical analysis and helped to draft the manuscript. FGu, FGa, AF and AG participated in the analysis and interpretation of data and helped to draft the manuscript. All authors read and approved the final manuscript. 


\section{Acknowledgements}

The coordinating investigators of EPIRCE Study group were: M.A. Álvarez-Lara; F. Vega; Laviades, P.J. Vives, J.M. Peña-Porta; J. Marco, A. Solís, A. Losada-González; G. Fernández-Fresnedo; J.F. Navarro, J.A. Sánchez-Joga; J. Fort, A. Martínez-Castelao, N. Fonseré; F. Tornero, M. Quintana; J. GrandeVilloria, A. Molina, B. Pozo, G. Torres; C. Fernández-Andrade; F. Vidaur, J. Manrique, M. Rodríguez; F. Caravaca, B. Cancho; A. Otero, L. González; A. Sánchez Casajús; F. García, M. San-Boixedau, K. López, E. Rubio, C. Bernis; M. Gironés; J.L. Asín; J. Hernández-Jaras, A. Rius, M. González-Rico.

\section{Funding}

The authors would like to express their gratitude for the support received from AMGEN, and the Spanish Instituto de Salud Carlos-III Grant (redlAPP [RD06/0018/0006]).

\section{Author details}

'Clinical Epidemiology Unit, Hospital Clínico Universitario, A Choupana, s/n, 15706, Santiago de Compostela, Spain. ${ }^{2}$ Instituto de Investigación Sanitaria de Santiago (IDIS), Santiago de Compostela, Spain. ${ }^{3}$ Nephrology Department, C. H.U. de Ourense, Ourense, Spain. ${ }^{4}$ Clinical Epidemiology Unit, Puerta de Hierro University Hospital, Madrid, Spain. ${ }^{5}$ Nephrology Department, Hospital Marques de Valdecilla, Santander, Spain.

Received: 22 February 2013 Accepted: 18 September 2013

Published: 16 October 2013

\section{References}

1. Rader DJ: Effect of insulin resistance, dyslipidemia, and intra-abdominal adiposity on the development of cardiovascular disease and diabetes mellitus. Am J Med 2007, 120(Suppl 1):S1-S8.

2. Goodwin P, Ennis M, Bahl M: High insulin levels in newly diagnosed breast cancer patients reflect underlying insulin resistance and are associated with components of the insulin resistance syndrome. Breast Cancer Res Treat 2009, 114:517-525.

3. Seriolo B, Ferrone C, Cutolo M: Log term anti-tumor necrosis factor a-treatment in patients with refractory rheumatoid arthritis: relationship between insulin resistance and disease activity. J Reumathol 2008, 35:355-357.

4. Chen J, Wildman RP, Hamm LL, Muntner P, Reynolds K, Whelton PK, He J: Third National Health and Nutrition Examination Survey. Association between inflammation and IR in U.S. nondiabetic adults: results from the Third National Health and Nutrition Examination Survey. Diabetes Care 2004, 27:2960-2965.

5. Eckel RH, Kahn R, Robertson RM, Rizza RA: Preventing cardiovascular disease and diabetes: a call for action from the American Diabetes Association and the American Heart Association. Circulation 2006, 113:2943-2946.

6. Kassi E, Pervanidou P, Kaltsas G, Chrousos G: Metabolic syndrome: definition and controversies. BMC Med 2011, 9:48.

7. Eckel RH, Grundy SM, Zimmet PZ: The metabolic syndrome. Lancet 2005, 365:1415-1428.

8. Alberti K, Eckel RH, Grundy SM, Zimmet PZ, Cleeman L, Donato KA Fruchart JC, James WP, Loria CM, Smith SC Jr: Harmonizing the metabolic syndrome: a join interim statement of the International Diabetes Federation Task Force on Epidemiology and Prevention; National Heart, Lung and Blood Institute; American Heart Association; World Heart Federation; International Atherosclerosis Society; and International Association for the Study of Obesity. Circulation 2009, 120:1640-1645.

9. Grundy SM, Cleeman JI, Daniels SR, Donato KA, Eckel RH, Franklin BA, Gordon DJ, Krauss RM, Savage PJ, Smith SC, Spertus JA, Costa F: Diagnosis and management of the metabolic syndrome: an American Heart Association/National Heart, Lung and Blood Institute Scientific Statement. Circulation 2005, 112:2735-2752.

10. Bray GA, Bellanger T: Epidemiology, trends and morbidities of obesity and the metabolic syndrome. Endocrine 2006, 29:109-117.

11. Danaei G, Finucane MM, Lu Y, Singh GM, Cowan MJ, Paciorek CJ, Lin JK, Farzadfar F, Khang Y-H, Stevens GA, Rao M, Ali MK, Riley LM, Robinson CA, Ezzati M: Global burden of metabolic risk factors of chronic diseases collaborating group (Blood Glucose). National, regional, and global trends in fasting plasma glucose and diabetes prevalence since 1980: systematic analysis of health examination surveys and epidemiological studies with 370 country-years and $2 \cdot 7$ million participants. Lancet 2011, 378:31-40.
12. Finucane MM, Stevens GA, Cowan MJ, Danaei G, Lin JK, Paciorek CJ, Singh GM, Gutierrez HR, Lu Y, Bahalin AN, Farzadfar F, Riley LM, Ezzati M: Global burden of metabolic risk factors of chronic diseases collaborating group (Body mass index). National, regional, and global trends in body-mass index since 1980: systematic analysis of health examination surveys and epidemiological studies with 960 country-years and 9.1 million participants. Lancet 2011, 377:557-567.

13. Lann D, LeRoith $D$ : Insulin resistance as the underlying cause for the metabolic syndrome. Med Clin North Am 2007, 91:1063-1077.

14. Antuna-Puente B, Disse E, Rabasa-Lhoret R, Laville M, Capeau J, Bastard JP: How can we measure insulin sensitivity/resistance? Diabetes Metab 2011, 37:179-188.

15. Hedblad B, Nilsson P, Janzon L, Berglund G: Relation between insulin resistance and carotid intima-media thickness and stenosis in non-diabetic subjects. Results from a cross-sectional study in Malmo, Sweden. Diabet Med 2000, 17:299-307.

16. Summer $A E$, Cowie CC: Ethnic differences in the ability of triglyceride levels to identify insulin resistance. Atherosclerosis 2008, 196:696-703.

17. Geloneze B, Repetto EM, Geloneze SR, Tambascia MA, Ermetice MN: The threshold value for insulin resistance (HOMA-IR) in an admixture population. IR in the Brazilian metabolic syndrome study. Diabetes Res Clin Pract 2006, 72:219-220.

18. Esteghamati A, Ashraf H, Esteghamati AR, Meysamie A, Khalizadeh O, Nakhjavani M, Abbasi M: Optimal threshold of homeostasis model assessment for insulin resistance in an Iranian population: the implication of metabolic syndrome to detect insulin resistance. Diabetes Res Clin Pract 2009, 84:279-287.

19. Marques-Vidal P, Mazoyer E, Bongard V, Gourdy P, Ruidavets JB, Drouet L, Ferreries J: Prevalence of insulin resistance syndrome in Southwestern France and its relationship with inflammatory and haemostatic markers. Diabetes Care 2002, 25:1371-1377.

20. Do HD, Lohsoosthorn V, Jiamjarasrangsi W, Lertmaharit S, Williams MA Prevalence of insulin resistance and its relationship with cardiovascular disease risk factors among Thai adults over 35 years old. Diabetes Res Clin Pract 2010, 89:303-308.

21. Bonora E, Kiechl S, Willeit J, Oberhollenzer F, Egger G, Targher G, Alberiche $\mathrm{M}$, Bonadonna RC, Muggeo M: Prevalence of insulin resistance in metabolic disorders. Diabetes 1995, 47:1643-1649.

22. Nakai $Y$, Fukushima M, Nakaishi S, Kishimoto H, Seino Y, Nagasaka S, Sakai $M$, Taniguchi A: The threshold value for insulin resistance on homeostasis model assessment of insulin sensitivity. Diabet Med 2002, 19:346-347.

23. Pepe MS: The Statistical Evaluation of Medical Tests for Classification and Prediction. New York: Oxford University Press; 2003.

24. Gayoso-Diz P, Otero-González A, Rodriguez-Alvarez MX, Gude F, Cadarso-Suarez C, García F, De Francisco A: IR index (HOMA-IR) levels in a general adult population: curves percentile by gender and age. The EPIRCE study. Diabetes Res Clin Pract 2011, 94:146-155.

25. Otero A, Gayoso P, García F, De Francisco AL: Epidemiology of chronic renal disease in the Galician population: results of the pilot Spanish EPIRCE study. Kidney Int 2005, 99(Suppl 1):S16-S19.

26. Otero A, De Francisco A, Gayoso P, Garcia F: Prevalence of chronic renal disease in Spain: results of the EPIRCE Study. Nefrologia 2010, 30:78-86.

27. Matthews DR, Hosker JP, Rudenski AS, Naylor BA, Treacher DF, Turner RC: Homeostasis model assessment: IR and beta-cell function from fasting plasma glucose and insulin concentration in man. Diabetologia 1985, 28:412-419.

28. Alberti KG, Zimmet P, Shaw J: IDF Epidemiology task force consensus group. The metabolic syndrome: a new world - wide definition. Lancet 2005, 366:1059-1062.

29. Expert Panel on Detection, Evaluation and Treatment of High Blood Cholesterol in Adults: Executive summary of the third report of the National Cholesterol Education Program (NCEP) expert panel on detection, evaluation and treatment of high blood cholesterol in adults (adult treatment panel III). JAMA 2001, 285:2486-2497.

30. Rodríguez-Álvarez MX, Roca-Pardiñas J, Cadarso-Suárez C: ROC curve and covariates: extending induced methodology to the non-parametric framework. Stat Comput 2011, 21:483-499.

31. Faraggi D: Adjusting receiver operating characteristic curves and related indices for covariates. The Statistician 2003, 52:179-192.

32. Rodríquez-Álvarez MX, Tahoces PG, Cadarso-Suárez C, Lado MJ: Comparative study of ROC regression techniques. Applications for the computer aided diagnostic system in breast cancer detection. Computational Statistics and Data Analysis 2011, 55:888-902. 
33. R Development Core Team. R: A Language and Environment for Statistical Computing R Foundation for Statistical Computing, Vienna, Austria. http:// www.R-project.org.

34. Robin X, Turck N, Hainard A, Tiberti N, Lisacek F, Sanchez J-C, Muller M: pROC: an open-source package for $\mathrm{R}$ and $\mathrm{S}+$ to analyze and compare ROC curves. BMC Bioinforma 2011, 7:77.

35. Esteghamati A, Ashraf H, Khalilzadeh O, Zandieh A, Nakhjavani M, Rashidi A, Haghazali M, Asgari F: Optimal cut-off of homeostasis model assessment of IR (HOMA-IR) for the diagnosis of metabolic syndrome: third national surveillance of risk factors of non-communicable diseases in Iran (SuRFNCD-2007). Nutr Metab 2010, 7:26.

36. Bertoni AG, Wong ND, Shea S, Ma S, Liu K, Preethi S, Jacobs DR, Wu C, Saad MF, Szkio M: Insulin resistance, metabolic syndrome and subclinical atherosclerosis: the Multi-Ethnic Study of Atherosclerosis (MESA). Diabetes Care 2007, 30:2951-2956.

37. Montecucco F, Steffens S, Mach F: Insulin resistance: a proinflammatory state mediated by lipid-induced signaling dysfunction and involved in atherosclerotic plaque instability. Mediators Inflamm 2008, 2008:767623.

38. Miccoli R, Biamchi C, Odoguardi L: Prevalence of the metabolic syndrome among Italian adults according to ATPII definition. Nutr Metab Cardiovasc Dis 2005, 15:250-254.

39. Ascaso JF, Romero P, Real JT, Priego A, Valdecabres C, Carmena R: Insulin resistance quantification by fasting insulin plasma values and HOMA index in a non-diabetic population. Med Clin (Barc) 2001, 117:530-533.

40. Tomé MA, Botana MA, Cadarso-Suarez C, Rego-Irateta A, Fernandez-Mariño A, Mato JA, Solache I, Perez-Fernandez R: Prevalence of metabolic syndrome in Galicia (NW Spain) on four alternative definitions and association with insulina resistance. J Endocrinol Invest 2009, 32:505-511.

41. Bonora E, Kiechl S, Willeit J, Oberhollenzer F, Egger G, Bonadonna RC, Muggeo M: Bruneck Study. Metabolic syndrome: epidemiology and more extensive phenotypic description. Cross-sectional data from Bruneck Study. Int J Obesity 2003, 27:1283-1289.

42. Ford ES, Giles WH, Dietz WH: Prevalence of metabolic syndrome among US adults. Findings from the Third National Health and Nutrition Examination Survey. JAMA 2002, 287:356-359.

doi:10.1186/1472-6823-13-47

Cite this article as: Gayoso-Diz et al:: Insulin resistance (HOMA-IR) cut-off values and the metabolic syndrome in a general adult population: effect of gender and age: EPIRCE cross-sectional study. BMC Endocrine Disorders 2013 13:47.

\section{Submit your next manuscript to BioMed Central and take full advantage of:}

- Convenient online submission

- Thorough peer review

- No space constraints or color figure charges

- Immediate publication on acceptance

- Inclusion in PubMed, CAS, Scopus and Google Scholar

- Research which is freely available for redistribution 